\title{
Monocyte chemoattractant protein-1 has prosclerotic effects both in a mouse model of experimental diabetes and in vitro in human mesangial cells
}

\author{
S. Giunti • G. H. Tesch • S. Pinach • D. J. Burt • \\ M. E. Cooper • P. Cavallo-Perin • G. Camussi • \\ G. Gruden
}

Received: 22 June 2007 / Accepted: 3 August 2007 / Published online: 30 October 2007

(C) Springer-Verlag 2007

\begin{abstract}
Aims/hypothesis Diabetic nephropathy is characterised by mesangial extracellular matrix accumulation. Monocyte chemoattractant protein-1 (MCP-1), a chemokine promoting monocyte infiltration, is upregulated in the diabetic glomerulus. We performed in vitro and in vivo studies to examine whether MCP-1 may have prosclerotic actions in the setting of diabetes, presumably via its receptor, chemokine (C-C motif) receptor 2 (CCR2), which has been described in mesangial cells.

Methods Human mesangial cells were exposed to recombinant human (rh)-MCP-1 (100 ng/ml) for 12, 24 and $48 \mathrm{~h}$ and to rh-MCP-1 (10, 100 and $200 \mathrm{ng} / \mathrm{ml})$ for $24 \mathrm{~h}$. Fibronectin, collagen IV and transforming growth factor, beta 1 (TGF- $\beta 1$ ) protein levels were measured by ELISA and pericellular polymeric fibronectin levels by western blotting. The intracellular mechanisms were investigated using specific inhibitors for CCR2, nuclear factor kappa B (NF-kB), p38 mitogen-activated protein kinase and protein kinase $C$, and an anti-TGF- $\beta 1$ blocking antibody. In both non-diabetic and streptozotocin-induced diabetic mice that were deficient or not
\end{abstract}

S. Giunti $(\bowtie) \cdot$ S. Pinach • D. J. Burt $\cdot$ P. Cavallo-Perin •

G. Camussi $\cdot$ G. Gruden

Department of Internal Medicine, University of Turin,

C.so AM Dogliotti, 14,

10126 Turin, Italy

e-mail: sara_giunti@katamail.com

G. H. Tesch

Department of Nephrology, Monash Medical Centre,

Clayton, Victoria, Australia

S. Giunti $\cdot$ M. E. Cooper

Danielle Alberti Memorial Centre for Diabetic Complications,

Diabetes and Metabolism Division,

Baker Heart Research Institute,

Melbourne, Victoria, Australia in MCP-1, glomerular fibronectin accumulation was examined by immunohistochemistry, while cortical $T g f-\beta 1$ (also known as $T g f b l)$ and fibronectin mRNA and protein levels were examined by real-time PCR and western blotting. Results In mesangial cells, MCP-1 binding to CCR2 induced a 2.5 -fold increase in fibronectin protein levels at $24 \mathrm{~h}$ followed by a rise in pericellular fibronectin, whereas no changes were seen in collagen IV production. MCP-1-induced fibronectin production was TGF- $\beta 1$ - and NF-kB-dependent. In diabetic mice, loss of MCP-1 diminished glomerular fibronectin protein production and both renal cortical $T g f-\beta 1$ and fibronectin mRNA and protein levels.

Conclusions/interpretation Our in vitro and in vivo findings indicate a role for the MCP-1/CCR2 system in fibronectin deposition in the diabetic glomerulus, providing a new therapeutic target for diabetic nephropathy.

Keywords CCR2 - Chemokine (C-C motif) receptor 2 . Diabetic nephropathy · Experimental diabetes · Fibronectin . Glomerulosclerosis · Glomerulus · MCP-1 - Mesangial cells · Monocyte chemoattractant protein-1

$\begin{array}{ll}\text { Abbreviations } \\ \text { CCR2 } & \text { chemokine (C-C motif) receptor 2 } \\ \text { HMC } & \text { human mesangial cell } \\ \text { HRP } & \text { horseradish peroxidase } \\ \text { ICAM-1 } & \text { intercellular adhesion molecule-1 } \\ \text { MAP kinase } & \text { mitogen-activated protein kinase } \\ \text { MCP-1 } & \text { monocyte chemoattractant protein-1 } \\ \text { NF-kB } & \text { nuclear factor kappa B } \\ \text { PKC } & \text { protein kinase C } \\ \text { rh } & \text { recombinant human } \\ \text { STZ } & \text { streptozotocin } \\ \text { TGF- } \beta 1 & \text { transforming growth factor, beta 1 }\end{array}$




\section{Introduction}

Diabetic nephropathy is characterised by excessive mesangial extracellular matrix accumulation. This leads to glomerular volume expansion and results eventually in glomerulosclerosis and progressive renal impairment [1]. Both hyperglycaemia and glomerular capillary hypertension play a key role in the pathogenesis of diabetic glomerulosclerosis [2]. In addition, a low degree of inflammation is also increasingly considered to contribute to the development of glomerular damage in diabetes [3].

Monocyte chemoattractant protein-1 (MCP-1) is a potent chemokine produced by activated monocytes and a variety of mesenchymal cells. In vitro, mesangial cell exposure to stretch and high glucose induces MCP-1 production resulting in monocyte chemotaxis [4]. In vivo, MCP-1 is overproduced in the glomeruli in experimental diabetes, an event paralleled by monocyte infiltration $[5,6]$. Infiltrating monocytes release inflammatory cytokines that enhance fibronectin production in mesangial cells [7], a possible mechanism whereby MCP-1 may contribute to fibronectin deposition in the diabetic glomeruli.

The MCP-1 receptor, chemokine (C-C motif) receptor 2 (CCR2), is predominantly present on circulating monocytes. However, a functionally active CCR2 receptor has been demonstrated in other cell types both in vitro [8-12] and in vivo [13-15], suggesting that MCP-1 may have other functional effects beyond monocyte recruitment [16]. Accordingly, we recently reported that in human mesangial cells (HMCs) MCP-1 binding to CCR2 induces intercellular adhesion molecule-1 (ICAM-1) production, leading to enhanced monocyte adhesion [17]. However, of particular relevance to the mesangial extracellular matrix accumulation seen in diabetes is the question of whether MCP-1 can also result in direct prosclerotic effects in HMCs. Thus, the present study was designed first to test in vitro in HMCs whether MCP-1 exerts such prosclerotic effects. Specifically, we investigated if MCP-1 binding to CCR2 induces fibronectin production and explored the potential intracellular mechanism/s involved. Second, we determined whether these in vitro findings were relevant in vivo by assessing extracellular matrix accumulation in diabetic $M c p-1$ (also known as $C c l 2$ ) knockout mice.

\section{Methods}

Materials

All materials were purchased from Sigma-Aldrich (St Louis, MO, USA) unless otherwise stated. Fetal calf serum was from Euroclone (Milan, Italy) and DMEM and TRIZOL reagent from Invitrogen (Carlsbad, CA, USA). The DNA-free DNAse was from Ambion (Austin, TX, USA) and the Superscript First Strand Synthesis System from Life Technologies BRL (Grand Island, NY, USA). The anti-transforming growth factor, beta 1 (TGF- $\beta 1$ ) neutralising antibody, the monoclonal anti-TGF- $\beta 1$ antibody and recombinant human (rh)-MCP-1 were obtained from R\&D Systems (Minneapolis, MN, USA). The Supersignal West Pico chemiluminescence substrate and both the goat anti-rabbit and the goat anti-mouse horseradish peroxidase (HRP)-linked antibodies were from Pierce (Rockford, IL, USA). SB202190 and the rabbit anti-fibronectin antibody were from Calbiochem (Nottingham, UK). The protein kinase $\mathrm{C}$ (PKC) peptide inhibitors $\mathrm{PKC}_{19-36}$ and SN50 were from Alexis (Nottingham, UK) and the TransAM nuclear factor kappa B (NF-kB) kit was from Active Motif (Rixensart, Belgium). The FITC-conjugated rabbit antimouse antibody, the rabbit anti-fibronectin antibody and the avidin/biotin blocking solution were from DAKOCytomation (Glostrup, Denmark). The TGF- $\beta 1$ Emax immunoassay system was from Promega (Southampton, UK) and Collagen IV ELISA from Exocell (Philadelphia, PA, USA). The biotinylated goat anti-rabbit antibody and the Vectastain Elite ABC Staining Kit were purchased from Vector Laboratories (Burlingame, CA, USA).

In vitro study

Cell culture Cells were isolated and characterised as described previously [18]. Normal renal cortex was obtained from the opposite tumour-free pole of nephrectomy specimens, removed for localised, capsulated grade 1 hypernephromas. Written informed consent was obtained from all donors. Tissue was analysed by light microscopy and by immunofluorescence to confirm the absence of tumour cells and to exclude the presence of glomerular abnormalities. Differentiated immortalised HMCs were obtained by infection of a pure primary culture with a hybrid Adeno5/SV40 virus [19]. Individual foci of immortalised cells were subcultured and characterised according to phenotype. A differentiated mesangial cell line was then selected and used in the study. Cells were cultured in DMEM medium, containing l-glutamine, $6 \mathrm{mmol} / \mathrm{l}$ glucose, supplemented with $20 \%$ (vol./vol.) heat-inactivated FCS, $100 \mathrm{U} / \mathrm{ml}$ penicillin and $100 \mu \mathrm{g} / \mathrm{ml}$ streptomycin in a humidified $5 \% \mathrm{CO}_{2}$ incubator at $37^{\circ} \mathrm{C}$. Studies were performed at passages 20 to 35 and cells were serumdeprived for $24 \mathrm{~h}$ prior to the experiment.

$T G F-\beta 1$, fibronectin and collagen type IV protein measurement Culture supernatant fractions from all experimental conditions were collected, centrifuged $(200 \times g)$ to remove cell debris and stored at $-80^{\circ} \mathrm{C}$ prior to analysis. For each experiment, TGF- $\beta 1$, fibronectin and collagen IV protein levels were determined within a single assay run. After 
activation of latent TGF- $\beta 1$ by acidification, total TGF- $\beta 1$ protein concentration was measured by ELISA (range: 16$1,000 \mathrm{pg} / \mathrm{ml}$; intra-assay CV: $1.6 \%$ ) using a mouse monoclonal and a rabbit polyclonal anti-human TGF- $\beta 1$. Fibronectin protein levels were measured using a competitive inhibition ELISA, as previously described (range $0.05-0.5 \mu \mathrm{g} / \mathrm{ml}$; intra-assay CV 5\%) [20]. Collagen IV levels were measured by indirect competitive ELISA (range: $0.02-2.5 \mu \mathrm{g} / \mathrm{ml}$; intra-assay and inter-assay $\mathrm{CV}<10 \%$ ) using collagen type IV-coated plates and a rabbit anticollagen type IV antibody. Results were adjusted for cell number determined by cell counting.

Measurements of pericellular polymeric fibronectin Levels of pericellular polymeric fibronectin were determined in deoxycholate-insoluble and sodium dodecyl sulfate (SDS)soluble protein extracts as previously described [20,21].

$N F-\kappa B$ activity Nuclear proteins were extracted and NF- $\mathrm{kB}$ activation determined using the NF- $\mathrm{KB}$ Trans-AM kit (Active Motif) according to the manufacturer's protocol. Briefly, $10 \mu \mathrm{g}$ nuclear protein extracts were transferred into wells containing the immobilised NF-KB (p65) consensus sequence and incubated for $1 \mathrm{~h}$ at $37^{\circ} \mathrm{C}$. After washing, an antibody that recognises an epitope on p65, which is accessible only when NF- $\mathrm{KB}$ is activated and bound to its target DNA, was added to the wells. Immunocomplexes were detected by addition of an HRP-conjugated antibody, the level of absorbance $(450 \mathrm{~nm})$, assessed in a microplate reader, reflecting the level of bound p65. Jurkat nuclear extracts were used as positive control. Specificity of the binding reaction was established through competition with an excess of wild-type consensus oligonucleotide and a lack of competition with a mutated consensus oligonucleotide.

Inhibition experiments Experiments were performed in the presence or in the absence of a panel of specific inhibitors/ blocking antibodies, which were added to the culture media $60 \mathrm{~min}$ prior to the experiment. Inhibition experiments on basal protein production were carried out simultaneously. RS102895 (6 $\mu \mathrm{mol} / 1)$, anti-TGF- $\beta 1$ neutralising antibody $(2 \mu \mathrm{g} / \mathrm{ml})$, SN50 $(18 \mu \mathrm{mol} / \mathrm{l}), \mathrm{SB} 202190(1 \mu \mathrm{mol} / \mathrm{l})$ and $\mathrm{PKC}_{19-36}(4 \mu \mathrm{mol} / \mathrm{l})$ were used to block CCR2, TGF- $\beta 1$, $\mathrm{NF}-\mathrm{KB}, \mathrm{p} 38$ mitogen-activated protein (MAP) kinase and PKC, respectively. The specificity and selectivity of the inhibitors used has been previously demonstrated [22-25].

In vivo study

Experimental animals $M c p-1$ deficient mice $\left(M c p-1^{-/}\right)$ were created by targeted gene disruption as previously described [26]. These mice were backcrossed eight times on to the C57BL/6J strain and compared with inbred Mcp-1-

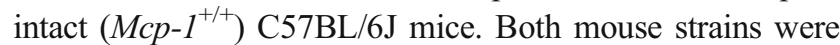
maintained on a normal diet under standard animal house conditions. Diabetes (blood glucose $>16 \mathrm{mmol} / \mathrm{l}$ ) was induced in both $M c p-I^{+/+}$and $M c p-I^{-/}$mice, weighing 21 to $26 \mathrm{~g}$ and aged 8 weeks, by intraperitoneal injections of streptozotocin (STZ)-citrate buffer $\left(125 \mathrm{mg} \mathrm{kg}^{-1}\right.$ day $\left.^{-1}\right)$ for two consecutive days. Blood glucose was measured between 09:00 and 10:00 hours via tail vein sampling on alert, nonfasted animals, using the diagnostic glucose oxidase enzymatic test (Medisense Glucometer; Abbott Laboratories, Bedford, MA, USA). Groups of Mcp- $1^{+/+}(n=8)$ and $M c p-1^{-/}$ $(n=8)$ diabetic mice with equivalent blood glucose levels were selected at week 2 and monitored until killed 12 and 18 weeks after STZ injection. Control non-diabetic $M c p-1^{+/+}$ $(n=8)$ and $M c p-1^{-/-}$mice $(n=8)$ were studied in parallel. A minority of mice in each diabetic group (10-15\%) began showing progressive weight loss associated with extreme hyperglycaemia (blood glucose $>30 \mathrm{mmol} / \mathrm{l}$ ) at 12 to 18 weeks and were given isophane insulin (Protophane; Novo Nordisk, Sydney, NSW, Australia) to prevent further weight loss, while maintaining diabetes. At 12 to 18 weeks post-diabetes the mice were killed and the kidneys rapidly dissected out. The right kidney was frozen in liquid nitrogen, then stored at $-80^{\circ} \mathrm{C}$ for both mRNA and protein analysis. The left kidney was stripped of its capsule, weighed, fixed in $10 \%$ formalin (vol./vol.) in PBS-at room temperature, then paraffinembedded for light microscopy. Both blood glucose and $\mathrm{HbA}_{1 \mathrm{c}}$ levels were measured in samples obtained via cardiac puncture after killing. Approval for these animal studies was obtained from the Monash Medical Centre Animal Ethics Committee in accordance with the Australian code of practice for the care and use of animals for scientific purposes.

Immunohistochemistry Fibronectin staining was performed on $4 \mu \mathrm{m}$ kidney paraffin sections ( $n=8$ per group). Briefly, sections were dewaxed, hydrated and quenched with $3 \%$ (vol./vol.) $\mathrm{H}_{2} \mathrm{O}_{2}$ in Tris-buffered saline ( $\mathrm{pH}$ 7.6) to inhibit endogenous peroxidase activity. This was followed by digestion with $0.4 \%$ pepsin (wt/vol.) in $0.01 \mathrm{~mol} / 1 \mathrm{HCl}$ at $37^{\circ} \mathrm{C}$ for $5 \mathrm{~min}$, and by blocking with Tris-buffered saline$0.5 \%$ skimmed milk (wt/vol.) for $15 \mathrm{~min}$. Subsequently, sections were incubated overnight with a primary polyclonal rabbit anti-human fibronectin antibody at $4{ }^{\circ} \mathrm{C}$. Following avidin/biotin blocking, sections were incubated with a secondary biotinylated goat anti-rabbit antibody and then with HRP-conjugated streptavidin. Peroxidase conjugates were visualised with the chromogen 3,3'-diaminobenzidine tetrahydrochloride in $0.08 \% \mathrm{H}_{2} \mathrm{O}_{2}$ (wt/vol.)-Tris-buffered saline. Finally, sections were counterstained with Mayer's haematoxylin, dehydrated and mounted.

Images were visualised under light microscopy (400× magnification; Olympus BX50, Olympus Optical, Hamburg, 
Germany), digitised with a JVC high-resolution camera (JVC, London UK), and quantitated using Optimas (Optimas 6.2Video Pro-32; Bedford Park, SA, Australia). Analysis was performed in a blinded fashion. On average, 20 randomly selected hilar glomerular tuft cross-sections were assessed per mouse [27] and eight mice were analysed per group. Results were calculated as percentage of positively stained tissue within the glomerular tuft.

Reverse-transcription and real-time polymerase chain reaction Total RNA was extracted from renal cortex using TRIZOL reagent and contaminating DNA removed using DNA-free DNAse. DNA-free RNA was reverse transcribed into cDNA using the Superscript First Strand Synthesis System (Life Technologies BRL).

Gene expression of both $T g f-\beta 1$ (also known as $T g f B 1$ ) and fibronectin was analysed by qRT-PCR using the Taqman system based on real-time detection of accumulated fluorescence (ABI Prism 7500; Perkin-Elmer, Foster City, CA, USA). Fluorescence for each cycle was analysed quantitatively and gene expression normalised relative to the expression of the housekeeping gene $18 \mathrm{~S}$ ribosomal RNA (18S rRNA Taqman Control Reagent kit; Applied Biosystems, ABI, Foster City, CA, USA), which was multiplexed together with the gene of interest. Probes and primers were designed using Primer Express software (Applied Biosystems and were purchased from Applied Biosystems. Primers and probes were as follows: $T g f-\beta 1$ : forward primer: GCAGTGGCTGAACCAAGGA, reverse primer: GCAGTGAGCGCTGAATCGA and probe: 6-FAM AAAGCCCTGTATTCCGT; fibronectin: forward primer ACATGGCTTTAGGCGGACAA, reverse primer ACATTC GGCAGGTATGGTCTTG and probe 6-FAM CCCC GTCAGGCTTA. Amplifications were performed under the following conditions: $50^{\circ} \mathrm{C}$ for $2 \mathrm{~min}, 95^{\circ} \mathrm{C}$ for $10 \mathrm{~min}, 50$ cycles at $94^{\circ} \mathrm{C}$ for $20 \mathrm{~s}$ and 50 cycles at $60^{\circ} \mathrm{C}$ for $1 \mathrm{~min}$.

Western blotting analysis Renal cortex was homogenised in RIPA buffer containing 1\% NP40 (vol./vol.), 0.5\% sodium deoxycholate (wt/vol.), $0.1 \%$ SDS (wt/vol.), $10 \mathrm{mmol} / 1$ $\beta$-mercaptoethanol and proteases inhibitors. Protein extracts were obtained by centrifugation at $14,000 \times \mathrm{g}$ for $10 \mathrm{~min}$ at $4^{\circ} \mathrm{C}$, preceded by a $45 \mathrm{~min}$ incubation period on ice. Total protein concentration was determined using an assay kit (BCA Total Protein Assay Kit; Pierce Biotechnology). We separated $30 \mu \mathrm{g}$ of total protein extracts by $7.5 \%$ (wt/vol.) (fibronectin) or $10 \%$ (wt/vol.) (TGF- $\beta 1)$ polyacrylamide gel electrophoresis and electrotransferred it to nitrocellulose membranes. The membranes were blocked in 3\% (wt/vol.) BSA-Tris-Tween-20 buffer (pH 7.6) and subsequently incubated overnight at $4^{\circ} \mathrm{C}$ with a rabbit anti-human fibronectin or a monoclonal anti-TGF- $\beta 1$ antibody. After washing, membranes were incubated with a goat anti-rabbit or a goat anti-mouse HRP-linked secondary antibody. Protein bands were detected by enhanced chemiluminescence and visualised on a Gel-Doc system (Bio-Rad, Milan, Italy). One band of $240 \mathrm{kDa}$ corresponding to cellular fibronectin and one band of $\sim 44 \mathrm{kDa}$ corresponding to TGF- $\beta 1$ were detected. Band intensities were quantified by densitometry. Equal protein loading was verified with Ponceau S staining of total proteins on the nitrocellulose membranes. Kidney cortexes from three to four mice were individually analysed per each group.

Data presentation and statistical analysis

The number of experiments, carried out in triplicate, is reported in the figure legends. All data are presented as mean \pm SEM. Data are expressed as fold change over control or arbitrary units. Student's $t$ test was used for the comparison between two groups. When more than two groups were studied, data were analysed by ANOVA and if significant, the Newman-Keuls was used for post hoc comparisons. Values of $p<0.05$ were considered significant.

\section{Results}

MCP-1 binding to CCR2 induces fibronectin, but not collagen type IV production in HMCs

Human mesangial cells were exposed to rh-MCP-1 (100 ng/ml) for 12,24 and $48 \mathrm{~h}$ and to increasing rh-MCP-1 concentrations $(10,100,200 \mathrm{ng} / \mathrm{ml})$ for $24 \mathrm{~h}$, and fibronectin protein levels were measured in the supernatant fractions. Endotoxin contamination of the rh-MCP-1 preparation was excluded by Limulus assay. Addition of rh-MCP-1 induced a statistically significant 2.5-fold increase in fibronectin protein levels at $24 \mathrm{~h}$ with a return to baseline values by $48 \mathrm{~h}$ (Fig. 1a). A statistically significant rise in fibronectin protein levels was seen at all MCP-1 doses (Fig. 1b) and the lowest effective concentration of $10 \mathrm{ng} / \mathrm{ml}$ was used in subsequent experiments. The addition of RS102895, a specific inhibitor of CCR2 signalling, completely abolished MCP-1-induced fibronectin production at $24 \mathrm{~h}(100 \%$ inhibition, $p<0.05)$, indicating that the effect observed was specific and mediated via the CCR2 receptor (Fig. 2). There was also a significant increase in pericellular polymeric fibronectin at $48 \mathrm{~h}(4.2 \pm$ 0.4 fold increase over control $p<0.05$ ), indicating that the increase in fibronectin in the supernatant fractions was followed by an enhanced incorporation of fibronectin in the matrix. In contrast, HMC exposure to $10 \mathrm{ng} / \mathrm{ml}$ of MCP-1 did not alter collagen type IV protein levels in the supernatant fractions ( $24 \mathrm{~h}: 1.02 \pm 0.10 ; 48 \mathrm{~h}: 1.18 \pm 0.15$ fold increase over control, $n=4, p=\mathrm{NS})$. 

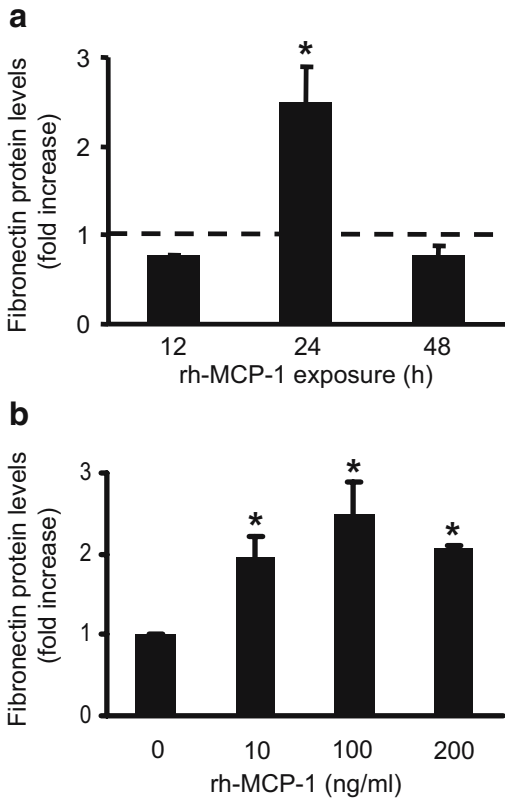

Fig. 1 MCP-1 induces fibronectin production in HMCs. Serumdeprived HMCs were exposed to (a) rh-MCP-1 (100 ng/ml) or vehicle (dashed line) for 12, 24 and $48 \mathrm{~h}$ and to (b) rh-MCP-1 (0, 10, 100, $200 \mathrm{ng} / \mathrm{ml}$ ) for $24 \mathrm{~h}$. Fibronectin protein levels were measured as described in Methods and are expressed as fold increase vs control $(n=3) .{ }^{*} p<0.05$ for rh-MCP-1 vs control

TGF- $\beta 1$ is the mediator of MCP-1-induced fibronectin production

Given the importance of TGF- $\beta 1$ in mesangial matrix production [28], we tested the role of TGF- $\beta 1$ in MCP1 -induced fibronectin. Exposure of HMCs to rh-MCP-1 $(10 \mathrm{ng} / \mathrm{ml})$ induced a significant increase in total TGF- $\beta 1$ protein levels at 12 and $24 \mathrm{~h}$ with a return to baseline values by $48 \mathrm{~h}$ (Fig. 3a). Moreover, the rise in fibronectin in response to rh-MCP-1 at $24 \mathrm{~h}$ was almost completely abolished by the addition of a specific anti-TGF- $\beta 1$ neutralising antibody $(83 \%$ inhibition $p<0.05)$ (Fig. 3b).

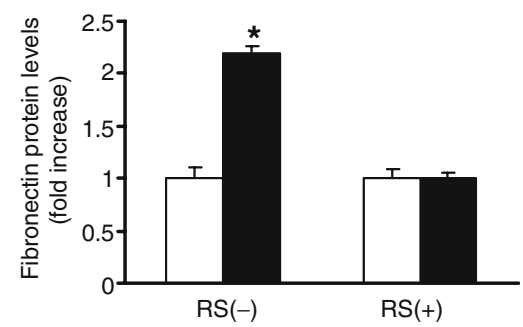

Fig. 2 MCP-1-induced fibronectin production occurs via the CCR2 receptor. Serum-deprived HMCs were exposed to either rh-MCP-1 $10 \mathrm{ng} / \mathrm{ml}$ (closed bars) or vehicle (open bars) for $24 \mathrm{~h}$ in the presence $[\mathrm{RS}(+)]$ and in the absence $[\mathrm{RS}(-)]$ of the specific CCR2 inhibitor, RS102895 $(6 \mu \mathrm{mol} / \mathrm{l})$. Results are expressed as fold increase over control $(n=3) .{ }^{*} p<0.05$ for rh-MCP1 vs others
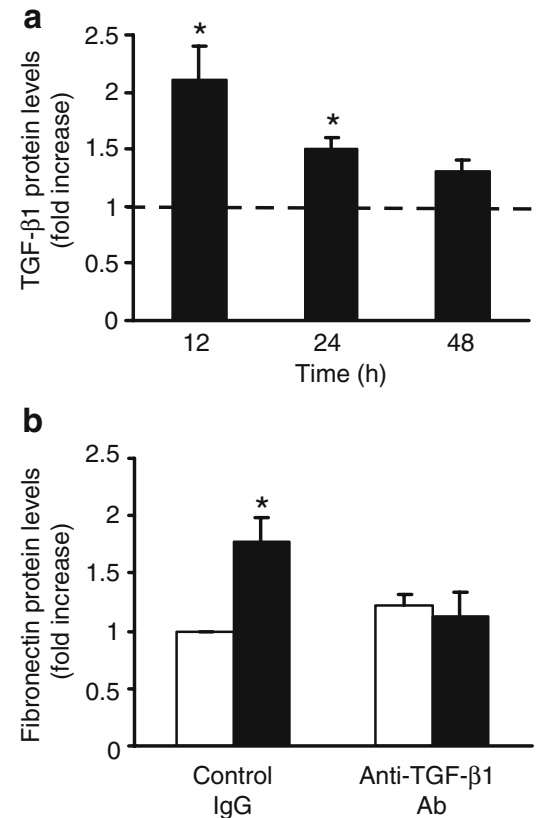

Fig. 3 MCP-1-induced fibronectin production is mediated by TGF$\beta 1$. a Serum-deprived HMCs were exposed to rh-MCP-1 $(10 \mathrm{ng} / \mathrm{ml})$ for 12,24 and $48 \mathrm{~h}$. TGF- $\beta 1$ protein levels were measured in the supernatant fractions and expressed as fold increase over control vehicle (dashed line) $(n=3) . * p<0.05$. b Serum-deprived HMCs were exposed for $24 \mathrm{~h}$ to rh-MCP-1 (10 ng/ml, closed bars) or vehicle (open bars) in the presence of an anti-TGF- $\beta 1$ neutralising antibody (Ab; $2 \mu \mathrm{g} / \mathrm{ml}$ ) or a control IgG. Fibronectin protein levels were measured in the supernatant fractions and expressed as fold increase over control vehicle $(n=3) .{ }^{*} p<0.05$

MCP-1-induced TGF- $\beta 1$ production is independent of PKC and $\mathrm{p} 38$ MAP kinase

Both PKC and p38 MAP kinase are considered important intracellular signalling molecules in the pathogenesis of diabetic glomerulosclerosis. These kinases are also key intracellular mediators of matrix component overproduction in mesangial cells in vitro $[2,20]$. To investigate the intracellular mechanisms by which rh-MCP-1 induces TGF- $\beta 1$ production, we examined the effect of $\mathrm{PKC}$ and p38 MAP kinase inhibition. MCP-1-induced secretion of TGF- $\beta 1$ was unaffected by the addition of either the p38 MAP kinase inhibitor SB202190 or the PKC inhibitor $\mathrm{PKC}_{19-36}$, indicating that this effect was independent of p38 MAP kinase and PKC (Fig. 4a).

NF- $\mathrm{kB}$ mediates MCP-1-induced TGF- $\beta 1$ production

An NF- $\mathrm{kB}$ binding site is present on the TGF- $\beta 1$ promoter [29]. Therefore, we tested whether NF- $k B$ was important in MCP-1-induced TGF- $\beta 1$ production. Preincubation of HMCs with SN50, a specific NF-kB inhibitor, significantly reduced the TGF- $\beta 1$ response to MCP- 1 (Fig. 4a). Further- 

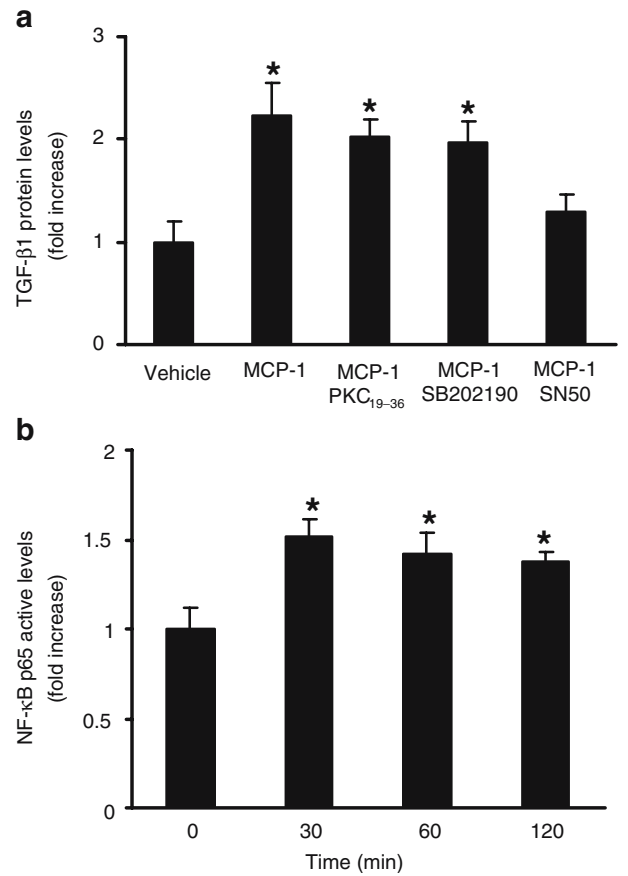

Fig. 4 Mechanisms of MCP-1-induced TGF- $\beta 1$ production. Serumdeprived HMCs were exposed to (a) rh-MCP-1 (10 ng/ml) or vehicle for $12 \mathrm{~h}$ in the presence and in the absence of the PKC inhibitor peptide $\mathrm{PKC}_{19-36}(4 \mu \mathrm{mol} / \mathrm{l})$, the p38 MAP kinase inhibitor SB202190 $(1 \mu \mathrm{mol} / 1)$ or the NF- $\mathrm{kB}$ inhibitor SN50 $(18 \mu \mathrm{mol} / 1)$. TGF- $\beta 1$ protein levels were measured in the supernatant fractions as described in Methods. Results are expressed as fold increase over control. $n=3$; ${ }^{*} p<0.05$ for MCP-1, MCP-1 + PKC $_{19-36}$ and MCP-1 + SB202190 vs control. b Serum-deprived HMCs were exposed to rh-MCP-1 (10 ng/ $\mathrm{ml}$ ) for $0,30,60$ and $120 \mathrm{~min}$. Active NF-kB p65 protein levels were measured in nuclear protein extracts as described in Methods and expressed as fold increase over baseline $(n=3)$. ${ }^{*} p<0.05$ for NF- $\mathrm{KB}$ at 30, 60 and $120 \mathrm{~min}$ vs $0 \mathrm{~min}$

more, rh-MCP-1 (10 ng/ml) induced a statistically significant 1.5-fold increase in active p65 NF- $\mathrm{KB}$ levels in nuclear proteins $(p<0.05)$ after $30 \mathrm{~min}$ of exposure (Fig. 4b).

MCP-1 deficiency attenuates glomerular fibronectin deposition in diabetic mice

To assess whether MCP-1 plays a role in fibronectin overproduction in vivo in experimental diabetes, we used immunohistochemistry to study glomerular fibronectin protein production in $M c p-I^{+/+}$and $M c p-1^{-/-}$mice 12 and 18 weeks after STZ injection.

Lack of MCP-1 production in this $M c p-1^{-/-}$murine model has previously been confirmed by in situ hybridisation [30]. Blood glucose and $\mathrm{HbA}_{1 \mathrm{c}}$ levels were significantly higher in the diabetic mice than in the nondiabetic animals, but there were no significant differences

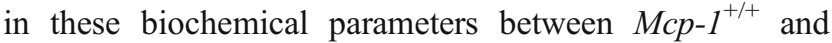

$M c p-1^{-/-}$diabetic mice. Furthermore, body weight was significantly lower in the diabetic than in the non-diabetic animals, but no difference was observed between $M c p-1^{+/+}$ and $M c p-1^{-/}$diabetic mice (Table 1).

The induction of diabetes was associated with an increase in fibronectin production in the $M c p-1^{+/+}$mice at 18 weeks after STZ injection (Fig. 5), whereas no differences were seen at the earlier time point of 12 weeks (8.6 \pm 1.7 vs $9.1 \pm 0.2 \%$ diabetic vs non-diabetic $M c p-1^{+/+}$ mice). Fibronectin protein overproduction was localised mainly to the mesangial matrix of glomeruli and, to a lesser extent, to the tubulointerstitium. In diabetic $\mathrm{Mcp}-\mathrm{I}^{-/-}$mice there was a reduction in fibronectin accumulation and quantitative analysis revealed a significant diminution in glomerular fibronectin staining in diabetic $M c p-1^{-/-}$mice compared with diabetic $M c p-1^{+/+}$mice, whereas no difference was found between non-diabetic $M c p-1^{+/+}$and $M c p-1^{-/-}$mice.

Loss of MCP-1 diminished fibronectin mRNA and protein levels in the renal cortex from diabetic mice

To confirm our immunohistochemistry findings with more quantitative techniques, we measured both fibronectin mRNA and protein levels in total renal cortex from $M c p$ $\mathrm{I}^{+/+}$and $M c p-1^{-/-}$mice both by real-time PCR and immunoblotting. Consistent with our immunohistochemistry data, we found a significant increase in fibronectin mRNA levels at 12 and 18 weeks in the diabetic $M c p-I^{+/+}$ mice, which was significantly reduced in the diabetic $M c p$ $1^{-/-}$mice (Fig. 6a). A similar finding was also observed at the protein level at 12 weeks (Fig. 6b).

MCP-1 deficiency reduced Tgf- $\beta 1$ mRNA and protein levels in the renal cortex from diabetic mice

To explore whether MCP-1 could play a role in modulating TGF- $\beta 1$ production in vivo in the context of diabetes, we studied both $T g f-\beta 1 \mathrm{mRNA}$ and protein levels in extracts of renal cortex from diabetic and non-diabetic $\mathrm{Mcp}_{-1} \mathrm{I}^{+/+}$and $M c p-1^{-1-}$ mice. Compared with non-diabetic mice, $T g f-\beta 1$ mRNA expression was significantly upregulated in the $M c p-I^{+/+}$mice 12 weeks after STZ injection, this effect being almost completely prevented in the diabetic $\mathrm{Mcp}-1^{-/-}$ mice (Fig. 6c). A similar trend in Tgf- $\beta 1$ mRNA expression was also observed at 18 weeks, although this did not reach statistical significance. In keeping with our mRNA findings, TGF- $\beta 1$ protein levels were significantly increased in diabetic $\mathrm{Mcp}_{-} \mathrm{I}^{+/+}$mice compared with non-diabetic $\mathrm{Mcp}-\mathrm{I}^{+/+}$ mice at 12 weeks, this increase being significantly blunted in diabetic mice lacking MCP-1 (Fig. 6d). No differences in either Tgf- $\beta 1$ mRNA or protein levels were seen between non-diabetic $\mathrm{Mcp}_{\mathrm{I}} \mathrm{I}^{+/+}$and $\mathrm{Mcp}-\mathrm{I}^{-/-}$mice. 
Table 1 Body characteristics of $M c p$ - 1 -intact and -deficient mice

\begin{tabular}{lllll}
\hline & Non-diabetic & & \multicolumn{2}{l}{ STZ-diabetic (18 weeks) } \\
\cline { 2 - 4 } & $M c p-1^{+/+}$ & $M c p-1^{-/-}$ & $M c p-1^{+/+}$ & $32.1 \pm 0.8^{* * *}$ \\
\hline Blood glucose (mmol/1) & $9.1 \pm 0.4$ & $8.9 \pm 0.4$ & $8.8 \pm 0.2^{* * *}$ & $29.9 \pm 2.3^{* * *}$ \\
HbA $_{1 \mathrm{c}}(\%)$ & $4.3 \pm 0.1$ & $4.5 \pm 0.2$ & $23.7 \pm 0.5^{* * *}$ & $25.8 \pm 0.7^{* * *}$ \\
Body weight $(\mathrm{g})$ & $27.4 \pm 0.7$ & $29.8 \pm 0.9$ & $1.1^{* * *}$ \\
\hline
\end{tabular}

Data are mean \pm SEM

$* * * p<0.001$ vs non-diabetic mice

\section{Discussion}

This study demonstrates that MCP-1 induces fibronectin production via a NF-KB- and TGF- $\beta 1$-dependent mechanism in HMCs and contributes to glomerular fibronectin and TGF- $\beta 1$ overproduction in experimental diabetes.

Exposure to MCP-1 induced a statistically significant 2.5-fold increase in fibronectin protein levels at $24 \mathrm{~h}$, which was comparable with the increase in extracellular matrix induced by MCP-1 in rat lung fibroblasts [31]. The rise in fibronectin protein levels in the supernatant fraction was followed by a significant increase in pericellular polymeric fibronectin, indicating enhanced fibronectin incorporation in the matrix. Fibronectin has been shown to promote
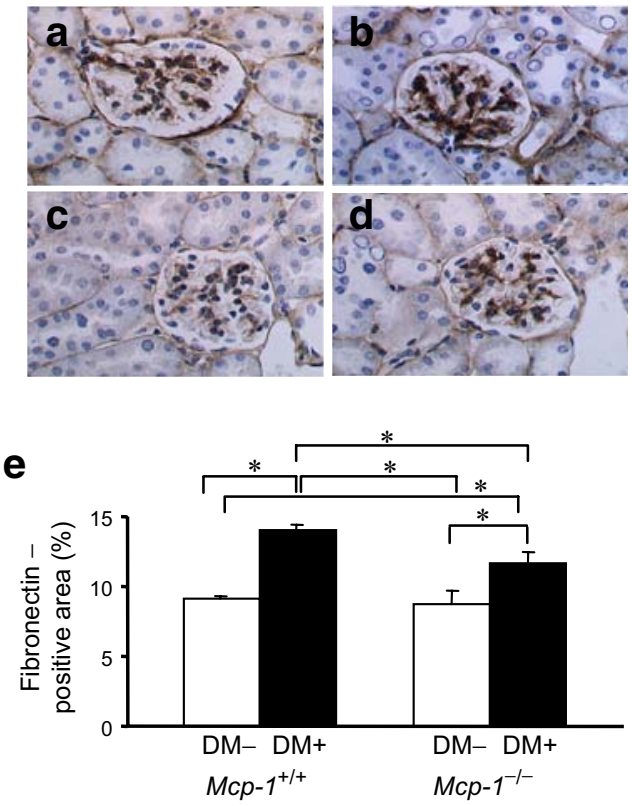

Fig. 5 MCP-1 deficiency attenuates glomerular fibronectin deposition in diabetic mice. Kidney paraffin sections from both diabetic $(\mathrm{DM}+)$ and non-diabetic (DM-) Mcp- $\mathrm{I}^{+/+}$and $M c p-1^{-1-}$ mice $(n=$ 8 per group) were stained for fibronectin as described in Methods. Representative examples of fibronectin glomerular staining are shown for (a) non-diabetic $M c p-1^{+/+}$, (b) diabetic $M c p-1^{+/+}$, (c) nondiabetic $M c p-1^{-/}$and (d) diabetic $M c p-1^{-/}$mice (400× magnification). e Quantification of proportional area of staining for fibronectin, $*_{p}<0.05$ monocyte entrapment and to enhance monocyte release of inflammatory cytokines [32]; thus, fibronectin deposition may favour amplification of the inflammatory process. No changes in collagen protein levels were seen in response to MCP-1, indicating that the direct prosclerotic effect of MCP-1 on HMCs was specific for fibronectin.

The lowest effective concentration of $10 \mathrm{ng} / \mathrm{ml} \mathrm{MCP}-1$ was within the higher physiological range, being comparable with that measured both in vitro in mesangial cells exposed to inflammatory cytokines [33] and in vivo at sites of inflammation [34]. The complete inhibition of MCP-1induced fibronectin production by RS102895 indicates that a specific effect of MCP-1 occurs via the CCR2 receptor. In HMCs, the CCR2 receptor also mediates $\mathrm{MCP}$ 1-induced ICAM-1 levels [17]. Therefore, HMCs produce a functionally active CCR2 receptor as previously shown both in vitro [8-12] and in vivo [13-15, 35] in other nonmononuclear cell types.

MCP-1-induced fibronectin production was mediated by TGF- $\beta 1$ as it was preceded by a rise in TGF- $\beta 1$ protein levels and significantly reduced by TGF- $\beta 1$ blockade. In HMCs several insults, including high glucose, stretch and angiotensin II [36-38], induce fibronectin production via a TGF- $\beta 1$-dependent mechanism. In vitro, in lung fibroblasts, TGF- $\beta 1$ is the mediator of MCP-1-induced collagen I production [31]. In vivo exogenous MCP-1 induces TGF$\beta 1$ formation in the isolated kidney, where no infiltrating inflammatory cells are present, suggesting a direct effect of MCP-1 on resident glomerular cells [39]. Our in vitro findings support this hypothesis and identify HMCs as a potential biological target for MCP-1.

Both PKC [40] and p38 MAP kinase [20] are key signalling molecules for the production of extracellular matrix components in HMCs. Furthermore, MCP-1 has been reported to activate $\mathrm{PKC}$ in tubular epithelial cells [41]. However, in our experiments inhibition of both p38 MAP kinase and PKC did not affect MCP-1-induced TGF$\beta 1$ secretion. On the contrary, in HMCs exposed to MCP-1 there was a rapid activation of $N F-\kappa B$, whereas inhibition of $N F-\kappa B$ reduced $T G F-\beta 1$ production. These data, indicating that NF- $\mathrm{kB}$ mediates MCP-1-induced TGF- $\beta 1$ production, are in line with previous studies showing an 

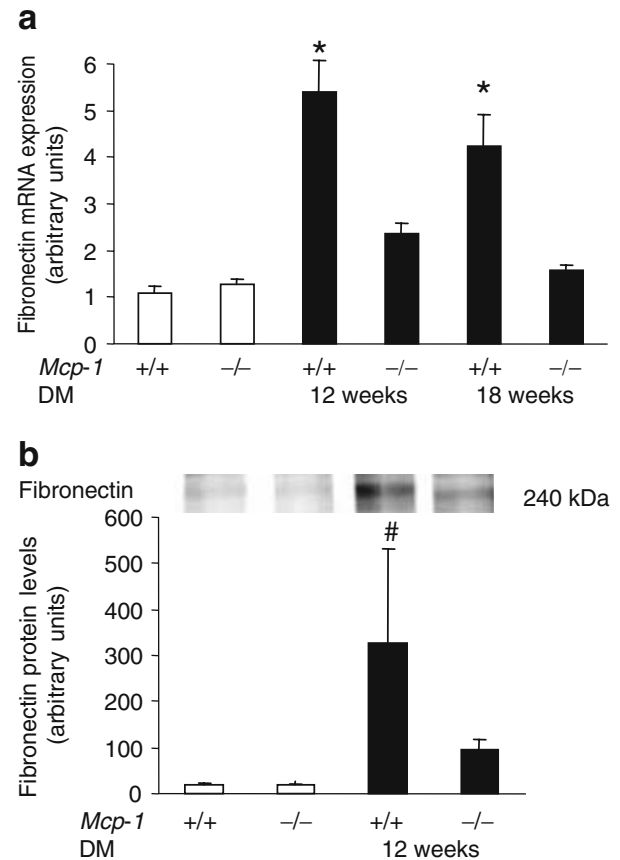

Fig. 6 MCP-1 deficiency attenuates renal fibronectin and Tgf- $\beta 1$ mRNA and protein levels in diabetic mice. Quantitative RT-PCR analysis of fibronectin (a) and $T g f-\beta 1$ (c) mRNA expression in total renal cortex from control (open columns) and diabetic (DM; closed columns) $M c p-1^{+/+}$and $M c p-1^{-/-}$mice at 12 and 18 weeks after the induction of diabetes. $n=6-9$ per group; ${ }^{*} p<0.05$ vs control $M c p-I^{+/+}$

NF- $\mathrm{kB}$ binding site in the TGF- $\beta 1$ promoter region [29] and $\mathrm{MCP}-1$-induced NF- $\mathrm{KB}$ activation in HMCs primed with IFN- $\gamma$ [42]. Interestingly, we have recently shown that MCP-1 production in response to high glucose and stretch in HMCs is also mediated by an NF- $\mathrm{kB}$-dependent mechanism [4]. The intracellular pathway mediating MCP-1/ CCR2-induced NF- $\mathrm{KB}$ activation remains undetermined; however, the signalling molecules phosphatidylinositol 3-kinase, Rho and janus kinase 2 are known to be activated by the MCP-1/CCR2 system [43-45] and can lead to NF-KB activation [46-48] in other cell types. Furthermore, the CCR2 receptor belongs to the $\mathrm{G}$ protein receptor family and the PI3K/Akt/NF-KB pathway is often activated in response to ligand to $\mathrm{G}$ protein receptor binding [46].

Previous studies have shown that inflammatory cytokines released by MCP-1-activated monocytes enhance fibronectin production in mesangial cells [7] and this was generally believed to be the sole mechanism linking MCP-1 to fibronectin overproduction. Our data showing that in HMCs MCP-1 binding to CCR2 directly induces fibronectin production via an NF- $\mathrm{KB}$ and TGF- $\beta 1$-dependent pathway provide a novel mechanism whereby MCP-1 can contribute to excess fibronectin deposition in the mesangium. Both resident glomerular cells and infiltrating monocytes are potential sources of MCP-1 within the glomerulus.
C
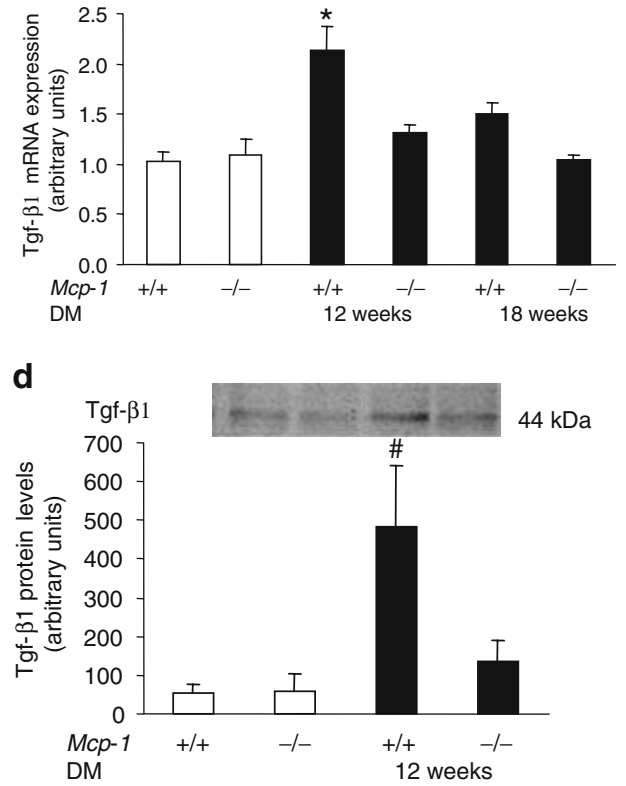

and $M c p-1^{-/}$and diabetic $M c p-1^{-/-}$at 12 and 18 weeks. Immunoblotting analysis of fibronectin (b) and TGF- $\beta 1$ (d) protein levels in total renal cortex extracts from control (open columns) and diabetic (closed columns) $M c p-I^{+/+}$and $M c p-1^{-/-}$mice at 12 weeks after the induction of diabetes. Representative immunoblots $(\mathbf{b}, \mathbf{d})$ are shown. $n=3-4$ per group; $\# p<0.02$ vs others

However, MCP-1 production is paralleled by CCR2 downregulation in HMCs [17, 49]. Therefore, MCP-1-induced fibronectin production is unlikely to occur via an autocrine mechanism. MCP-1 released by infiltrating monocytes and/ or neighbouring glomerular cells (e.g. podocytes) is more likely to be implicated.

To assess whether MCP-1 plays a role in fibronectin accumulation in vivo in experimental diabetes, we compared fibronectin deposition within the glomeruli in diabetic $M c p-1^{-/}$and $M c p-I^{+/+}$mice. The phenotype of $M c p-1^{-/-}$mice used in this study has been previously described [26]. The induction of diabetes by STZ in this model has been previously established and a recent study has demonstrated suppression of macrophage infiltration, albuminuria and renal injury in this model, although specific assessment of a potential link to fibronectin accumulation was not examined [30]. A significant increase in glomerular fibronectin protein levels was seen in the diabetic $M c p-1^{+/+}$ mice at 18 weeks, while no changes were observed at 12 weeks. Fibronectin accumulation within the glomeruli was significantly suppressed in diabetic $\mathrm{Mcp}^{-1^{-/}}$mice, providing in vivo evidence that MCP-1 contributes to excess fibronectin deposition.

These immunohistochemical findings were confirmed by western blotting and real time-PCR analysis of renal cortex, 
showing that both mRNA and protein fibronectin overproduction in diabetic $M c p-1^{+/+}$mice was almost completely abolished in the diabetic $M c p-1^{-/-}$mice. Moreover, neither mRNA nor protein TGF- $\beta 1$ overproduction occurred in the $M c p-1^{-/}$diabetic mice, indicating that in vivo, in the context of diabetes, MCP-1 can also modulate the production of TGF- $\beta 1$.

Blood glucose levels and $\mathrm{HbA}_{1 \mathrm{c}}$ were similar in diabetic $M c p-1^{-/}$and $M c p-1^{+/+}$mice, consistent with the beneficial effect of MCP-1 deficiency observed in these mice being independent of the glycaemic factor. Furthermore, there was no difference in fibronectin and TGF- $\beta 1$ levels between nondiabetic $\mathrm{Mcp}_{-} \mathrm{I}^{+/+}$and $\mathrm{Mcp}-\mathrm{I}^{-/-}$mice, suggesting that the absence of MCP-1 specifically affects diabetes-induced TGF- $\beta 1$ and fibronectin levels and does not play an important role in the absence of hyperglycaemia.

The present study has identified a novel action of MCP-1, presumably via its receptor CCR2, namely its ability to induce extracellular matrix accumulation in HMCs. The in vivo study provides further evidence linking glomerular MCP-1 levels to increased fibronectin and TGF- $\beta 1$ production in a diabetic milieu. Although these results cannot be directly translated into day-to-day clinical practice, they provide a convincing proof of concept of the relevance of the MCP-1/CCR2 system in the pathogenesis of glomerular damage. In the context of other actions of MCP-1 in inducing monocyte/macrophage infiltration in the kidney and a similar phenomenon in atherosclerosis [50], another major complication of diabetes, these findings make the MCP-1/CCR-2 pathway an attractive target for developing new therapies directed towards reducing the burden of diabetic complications, including nephropathy.

Acknowledgements This work was supported by the University of Turin and by the European Foundation for the Study of Diabetes/Lilly European Diabetes Research Programme.

Duality of interest The authors declare that there is no duality of interest associated with this manuscript.

\section{References}

1. Mauer SM, Steffes MW, Ellis EN, Sutherland DE, Brown DM, Goetz FC (1984) Structural-functional relationships in diabetic nephropathy. J Clin Invest 74:1143-1155

2. Cooper ME (2001) Interaction of metabolic and haemodynamic factors in mediating experimental diabetic nephropathy. Diabetologia 44:1957-1972

3. Furuta T, Saito T, Ootaka T et al (1993) The role of macrophages in diabetic glomerulosclerosis. Am J Kidney Dis 21:480-485

4. Gruden G, Setti G, Hayward A et al (2005) Mechanical stretch induces monocyte chemoattractant activity via an NF- $\mathrm{KB}$-dependent monocyte chemoattractant protein-1-mediated pathway in human mesangial cells: inhibition by rosiglitazone. J Am Soc Nephrol $16: 688-696$
5. Sassy-Prigent C, Heudes D, Mandet C (2000) Early glomerular macrophage recruitment in streptozotocin-induced diabetic rats. Diabetes 49:466-475

6. Kato S, Luyckx VA, Ots M et al (1999) Renin-angiotensin blockade lowers MCP-1 expression in diabetic rats. Kidney Int 56:1037-1048

7. Pawluczyk IZ, Harris KP (1998) Cytokine interactions promote synergistic fibronectin accumulation by mesangial cells. Kidney Int 54:62-70

8. Viedt C, Vogel J, Athanasiou T et al (2002) Monocyte chemoattractant protein-1 induces proliferation and interleukin-6 production in human smooth muscle cells by differential activation of nuclear factor- $\mathrm{kB}$ and activator protein-1. Arterioscler Thromb Vasc Biol 22:914-920

9. Weber KS, Nelson PJ, Grone HJ, Weber C (1999) Expression of CCR2 by endothelial cells: implications for MCP-1 mediated wound injury repair and in vivo inflammatory activation of endothelium. Arterioscler Thromb Vasc Biol 19:2085-2093

10. Lundien MC, Mohammed KA, Nasreen N et al (2002) Induction of MCP-1 expression in airway epithelial cells: role of CCR2 receptor in airway epithelial injury. J Clin Immunol 22:144-152

11. Andjelkovic AV, Song L, Dzenko KA, Cong H, Pachter JS (2002) Functional expression of CCR2 by human fetal astrocytes. J Neurosci Res 70:219-231

12. Coughlan CM, McManus CM, Sharron M et al (2000) Expression of multiple functional chemokine receptors and monocyte chemoattractant protein-1 in human neurons. Neuroscience 97:591-600

13. Banisadr G, Queraud-Lesaux F, Boutterin MC et al (2002) Distribution, cellular localization and functional role of CCR2 chemokine receptors in adult rat brain. J Neurochem 81:257-269

14. Warren GL, Hulderman T, Mishra D et al (2005) Chemokine receptor CCR2 involvement in skeletal muscle regeneration. FASEB J 19:413-415

15. Moore BB, Kolodsick JE, Thannickal VJ et al (2005) CCR2mediated recruitment of fibrocytes to the alveolar space after fibrotic injury. Am J Pathol 166:675-684

16. Roque M, Kim WJ, Gazdoin M et al (2002) CCR2 deficiency decreases intimal hyperplasia after arterial injury. Arterioscler Thromb Vasc Biol 22:554-559

17. Giunti S, Pinach S, Arnaldi L et al (2006) The MCP-1/CCR2 system has direct proinflammatory effects in human mesangial cells. Kidney Int 69:856-863

18. Gruden G, Thomas S, Burt D et al (1997) Mechanical stretch induces vascular permeability factor in human mesangial cells: mechanisms of signal transduction. Proc Natl Acad Sci U S A 94:12112-12116

19. Conaldi PG, Biancone L, Bottelli A et al (1998) HIV-1 kills renal tubular epithelial cells in vitro by triggering an apoptotic pathway involving caspase activation and Fas upregulation. J Clin Invest 102:2041-2049

20. Gruden G, Zonca S, Hayward A et al (2000) ATII mechanical stretch-induced fibronectin and transforming growth factor-beta1 production in human mesangial cells is p38 mitogen-activated protein kinase-dependent. Diabetes 49:655-661

21. Choi MG, Hynes RO (1979) Biosynthesis and processing of fibronectin in NIL.8 hamster cells. J Biol Chem 254:12050-12055

22. Mirzadegan T, Diehl F, Ebi B et al (2000) Identification of the binding site for a novel class of CCR2b chemokine receptor antagonists: binding to a common chemokine receptor motif within the helical bundle. J Biol Chem 275:25562-25571

23. Jiang Y, Chen C, Li Z et al (1996) Characterization of the structure and function of a new mitogen-activated protein kinase (p38beta). J Biol Chem 271:17920-17926

24. Lin YZ, Yao SY, Veach RA, Torgerson TR, Hawiger J (1995) Inhibition of nuclear translocation of transcription factor NF-kB by a synthetic peptide containing a cell membrane-permeable motif and nuclear localization sequence. J Biol Chem 270:14255-14258 
25. House C, Kemp BE (1987) Protein kinase C contains a pseudosubstrate prototope in its regulatory domain. Science 238:1726-1728

26. Lu B, Rutledge BJ, Gu L et al (1998) Abnormalities in monocyte recruitment and cytokine expression in monocyte chemoattractant protein 1-deficient mice. J Exp Med 187:601-608

27. Lassila M, Seah KK, Allen TJ et al (2004) Accelerated nephropathy in diabetic apolipoprotein e-knockout mouse: role of advanced glycation end products. J Am Soc Nephrol 15:2125-2138

28. Ziyadeh FN (2004) Mediators of diabetic renal disease: the case for TGF-Beta as the major mediator. J Am Soc Nephrol 15:S55-S57

29. Lan Y, Zhou Q, Wu ZL (2004) NF-kB involved in transcription enhancement of TGF-beta 1 induced by Ox-LDL in rat mesangial cells. Chin Med J (Engl) 117:225-230

30. Chow FY, Nikolic-Paterson DJ, Ozols E, Atkins RC, Rollins BJ, Tesch GH (2006) Monocyte chemoattractant protein-1 promotes the development of diabetic renal injury in streptozotocin-treated mice. Kidney Int 69:73-80

31. Gharaee-Kermani M, Denholm EM, Phan SH (1996) Costimulation of fibroblast collagen and transforming growth factor beta1 gene expression by monocyte chemoattractant protein-1 via specific receptors. J Biol Chem 271:17779-17784

32. Chana RS, Martin J, Rahman EU, Wheeler DC (2003) Monocyte adhesion to mesangial matrix modulates cytokine and metalloproteinase production. Kidney Int 63:889-898

33. Grandaliano G, Valente AJ, Rozek MM, Abboud HE (1994) Gamma interferon stimulates monocyte chemotactic protein (MCP-1) in human mesangial cells. J Lab Clin Med 123:282-289

34. Tylaska LA, Boring L, Weng W et al (2002) Ccr2 regulates the level of MCP-1/CCL2 in vitro and at inflammatory sites and controls $\mathrm{T}$ cell activation in response to alloantigen. Cytokine 18:184-190

35. Spinetti G, Wang M, Monticone R, Zhang J, Zhao D, Lakatta EG (2004) Rat aortic MCP-1 and its receptor CCR2 increase with age and alter vascular smooth muscle cell function. Arterioscler Thromb Vasc Biol 24:1397-1402

36. Kreisberg JI, Garoni JA, Radnik R, Ayo SH (1994) High glucose and TGF beta 1 stimulate fibronectin gene expression through a cAMP response element. Kidney Int 46:1019-1024

37. Hirakata M, Kaname S, Chung UG et al (1997) Tyrosine kinase dependent expression of TGF-beta induced by stretch in mesangial cells. Kidney Int 51:1028-1036

38. Kagami S, Border WA, Miller DE, Noble NA (1994) Angiotensin II stimulates extracellular matrix protein synthesis through induction of transforming growth factor-beta expression in rat glomerular mesangial cells. J Clin Invest 93:2431-2437

39. Wolf G, Jocks T, Zahner G, Panzer U, Stahl RA (2002) Existence of a regulatory loop between MCP-1 and TGF-beta in glomerular immune injury. Am J Physiol Renal Physiol 283:F1075-F1084

40. Ikehara K, Tada H, Kuboki K, Inokuchi T (2003) Role of protein kinase $\mathrm{C}$-angiotensin II pathway for extracellular matrix production in cultured human mesangial cells exposed to high glucose levels. Diabetes Res Clin Pract 59:25-30

41. Viedt C, Dechend R, Fei J, Hansch GM, Kreuzer J, Orth SR (2002) MCP-1 induces inflammatory activation of human tubular epithelial cells: involvement of the transcription factors, nuclear factor-kappaB and activating protein-1. J Am Soc Nephrol 13:1534-1547

42. Schwarz M, Wahl M, Resch K, Radeke HH (2002) IFNgamma induces functional chemokine receptor expression in human mesangial cells. Clin Exp Immunol 128:285-294

43. Arefieva TI, Kukhtina NB, Antonova OA, Krasnikova TL (2005) MCP-1-stimulated chemotaxis of monocytic and endothelial cells is dependent on activation of different signaling cascades. Cytokine 31:439-446

44. Stamatovic SM, Keep RF, Kunkel SL, Andjelkovic AV (2003) Potential role of MCP-1 in endothelial cell tight junction 'opening': signaling via Rho and Rho kinase. J Cell Sci 116:4615-4628

45. Mellado M, Rodriguez-Frade JM, Aragay A et al (1998) The chemokine monocyte chemotactic protein 1 triggers Janus kinase 2 activation and tyrosine phosphorylation of the CCR2B receptor. J Immunol 161:805-813

46. Xie P, Browning DD, Hay N, Mackman N, Ye RD (2000) Activation of NF-kappa B by bradykinin through a Galpha(q)and Gbeta gamma-dependent pathway that involves phosphoinositide 3-kinase and Akt. J Biol Chem 275:24907-24914

47. Cammarano MS, Minden A (2001) Dbl and the Rho GTPases activate NF kappa B by I kappa B kinase (IKK)-dependent and IKK-independent pathways. J Biol Chem 276:25876-25882

48. Digicaylioglu M, Lipton SA (2001) Erythropoietin-mediated neuroprotection involves cross-talk between Jak2 and NF-kappaB signalling cascades. Nature 412:641-647

49. Janssen U, Sowa E, Marchand P, Floege J, Phillips AO, Radeke $\mathrm{HH}$ (2002) Differential expression of MCP-1 and its receptor CCR2 in glucose primed human mesangial cells. Nephron 92:797-806

50. Charo IF, Taubman MB (2004) Chemokines in the pathogenesis of vascular disease. Circ Res 95:858-866 